\title{
Phosphogypsum Management Perspectives. Massive Valorization or Massive Storage?
}

\author{
Hajer Maazoun and Mounir Bouassida* \\ École Nationale d'Ingénieurs de Tunis, Université de Tunis El Manar, Tunisia \\ *Corresponding Author: Mounir Bouassida, École Nationale d'Ingénieurs de Tunis, Université de Tunis El Manar, Tunisia.
}

Received: June 05, 2019; Published: July 22, 2019

DOI: 10.31080/ASAG.2019.03.0584

\begin{abstract}
Phosphogypsum (PG) management is a challenge to the authorities worldwide especially because of environmental concerns. PG valorization has been essential as its storage has reached critical quantities. Several studies were carried out in this context to focus on the possibilities of PG valorization especially in agriculture and civil engineering fields as massive valorization axis. However, PG valorization is still quite limited which makes of its storage into embankments a temporary alternative to manage it. Although, PG deposit into embankments is ground intensive and limited by the critical areas and height they can reach. The study of new alternatives is progressing to help optimizing storage areas till putting PG valorization in action.
\end{abstract}

Keywords: Phosphogypsum; Massive; Valorization; Storage; Environmental; Geotechnical

\section{Abbreviations}

PG: Phosphogypsum; CTG: Chemical Tunisian Group.

\section{Introduction}

Till 2017, the world counts a population of more than 7 milliards according to the United Nations statistics. World Population Prospects [1]. Providing the nutritional needs of such a population is a challenge that cannot be solved based only on the biological fertilizers. Hence, the use of chemical fertilizers is inevitable with an annual progression ratio of 5\% in 2009 according to the MITSI (Moroccan Institute of Technical and scientific information). Phosphogypsum is an industrial residue resulting from phosphoric acid $\left(\mathrm{P}_{2} \mathrm{O}_{5}\right)$ which is used in chemical fertilizers production. However, the production of 1 tone of $\mathrm{P}_{2} \mathrm{O}_{5}$ results on 5 tons of PG TCG (2014). Till 2013, the production of Phosphogypsum counts 3 Billion of tones around the world IAEA [2]. This residue used to be either stored in the vicinities of the production factories or rejected into the sea. Nevertheless, these two methods of management showed critical limitations. In fact, PG storage requires intensive areas Bouassida [3], Bouassida [4], Chaari [5], Maazoun and Bouassida
[6] while its reject into the sea causes its pollution and threats the maritime fauna and flora IAEA [2]. Hence, Phosphogypsum valorization has been subject of several researches for more than half a decade now. Various valorization options have been considered leading to conclude that agriculture is the more PG consumer method Hilton [7].

\section{Phosphogypsum Management Methods}

Phosphogypsum can be managed according to three methods. It is either rejected into the sea, or stored into embankments or valorized.

\section{Phosphogypsum deposit into the sea}

Phosphogypsum used to be deposited into the sea, as early experienced in many countries like the United States of America, Spain and the United Kingdom. However, its reject into the sea was forbidden in these countries since the 1990's for environmental concerns while the Moroccan continued depositing more than 15 million tons of PG annually into the Atlantic Ocean IAEA [2], International Maritime Organization [8]. Nevertheless, although Tunisia still rejects PG in Gabes Gulf, of the Mediterranean Sea, it is con- 
sidered as a world leader in the PG contaminated areas remediation via TAPARURA project, occurred to repair the environmental alteration caused to Sfax City coast by the NPK factory IAEA [2].

Phosphogypsum storage into embankments

Among the 3 billion tons of PG produced till 2013 IAEA [2], 85\% are either rejected into the sea or stored into embankments in the vicinities of phosphoric acid production factories Moalla., et al. [9]. This method of management allows storing important quantities of Phosphogypsum in specific areas. However, many embankments around the world have known considerable extensions such as the wet deposited embankment of Sfax, Tunisia, with $56 \mathrm{~m}$ of height, $53 \mathrm{Ha}$ of area and $32^{\circ}$ of slope Bouassida [4] and the dry deposited embankment of Skhira city, Tunisia too, 55m height, $112 \mathrm{Ha}$ area and $1 / 4$ to $2 / 3$ slopes Chaari [5]. The wet phosphogypsum embankments in Huelva, Spain, does not exceed $28 \mathrm{~m}$ of height Valverde-Palacios., et al. [10], this of Mianzhu City, Baiyi Village, China, is almost of $20 \mathrm{~m}$ height www.greenpeace.org [11], while the New Wales facility wet embankment at Mulberry, Florida, is expected to reach almost $91 \mathrm{~m}$ in height by 2023 [12].

\section{Phosphogypsum valorization}

The United States Environmental Protection Agency (USEPA) classified Phosphogypsum as a Technologically Enhanced Naturally Occurring Radioactive Material (TENORM) Tayibi., et al. [13]. Hence, it is rather classified as a co-product, in place of waste. Based on its presence with abundant quantities and its encouraging economic potential, several studies were carried out to focus on the possibilities of its valorization in different fields in an attempt to its use in different ways, especially chemical industry and civil engineering Tayibi., et al. [13]. However, the most successful valorization axis ever found is in fertilizing the saline soils, as experienced in Huelva, Spain Valverde-Palacios., et al. [10], Hilton [7]. In fact, Phosphogypsum was used for agricultural uses in many countries around the world such as Spain, Australia, Brazil, Egypt, India, Kazakhistan, Pakistan, Syria and the USA. In Brazil, $40 \%$ of the produced PG is used for agricultural applications IAEA [2]. In California, USA, an embankment coming from Idaho and Wyoming phosphate was completely used for agriculture before this application was forbidden by the regulation in 1989. In Florida, USA, a small quantity of $P G$ continued to be used in peanut growing although the used PG ratio does not exceed $0.03 \%$ of the total PG produced in Florida. In the European Union, PG was used for soil fertilization under the calcium phosphate category IAEA [2].
Soil fertilizing with Phosphogypsum

The soils fertilization using Phosphogypsum allows land repairing (rehabilitation). It recovers the soil productivity, prevents crusts formation and improves water retention as well as it ameliorates trees' growing IAEA [2]. Phosphogypsum improves lands, and allows recovering saline soils as well. This is achieved by reducing the soil toxicity by sodium and aluminum, increasing calcium and sulfurs dissolved from PG, and increasing ammoniac and water retention by the soil IAEA [2]. The use of Phosphogypsum as a fertilizer, generally at a rate of $100-600 \mathrm{~kg} / \mathrm{Ha}$, proved its efficiency for many species like carrots, lemons, peach, sugar, avocado, coffee, pepper, beans, corns, tea, cotton, rice, tomatoes, beetroots, onions, peanuts and oranges IAEA [2].

Phosphogypsum valorization in agriculture compared to other fields

In contrast to numerous applications in civil engineering Felfoul., et al. [14], Tayibi., et al. [13] and chemical industries Tayibi., et al. [13], Colombel [15], Al-Jabbari., et al. [16], Singh., et al. [17], PG is generally used in its generation state without any modification. Recently produced, wet and unaltered, it is diffused on the land according to conventional diffusion methods. However, it is sometimes required purifying PG from acid water and impurities. Hence, to keep it competitive to natural gypsum which is abundant in many countries, it should be taken into consideration that PG purification should be carried out at the lowest cost. I his context, PG extracted from an embankment from north of Florida, USA, was first exposed to rain water for one year, reducing its $\mathrm{pH}$ to 5 , before it was exploited in agriculture IAEA [2]. Although PG valorization in road field promises the mobilization of big quantities of Phosphogypsum, it is limited by the climate conditions and its application is restricted to arid areas Felfoul., et al [14]. In contrast, PG valorization in agriculture is intensive PG consumer. In fact, a big area nearly Huelva, Spain, was recovered using PG and is now among the productive lands (Figure 1) IAEA [2], Hilton [7]. This site is particularly important for the risks evaluation as it is the only referenced site in the world which can be used to study the impact of 40 years of non-stop discharge of PG by land recovery IAEA [2].

This reveals many thoughts to some countries like Tunisia, where almost 1,5 Million Ha of land suffer from soil salinity, which is about $10 \%$ of the country's total area Hachicha [18]. Salinity presents a constraining factor for agriculture as the important rate 
of salts imported by irrigation water can cause lands sterility due to the lack of adequate managements. Hence, the integration of PG in agricultural applications in Tunisia is strongly recommended. It is a valorization option to absorb important quantities of $\mathrm{PG}$, however being lesser than produced quantities.
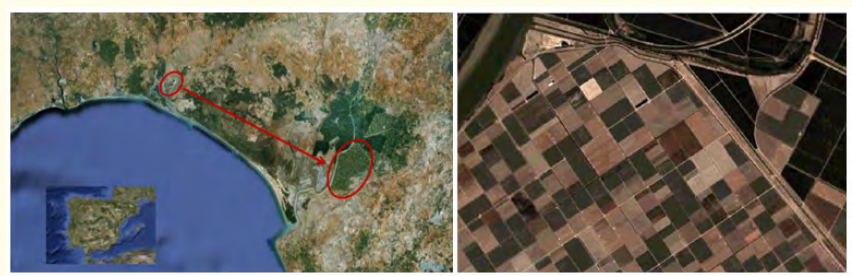

Figure 1: Land recovered using PG in South West of Spain, Sevilla University IAEA (2013), Hilton (2010).

Limitations of phosphogypsum valorization - need of massive storage

Although several researches revealed that Phosphogypsum can be valorized in civil engineering, chemical industry and agriculture fields, only $15 \%$ of the worldwide produced quantity is put into valorization, the other $85 \%$ is stored at embankments using either wet or dry process [9]. This is explained especially by the high cost of PG purification which can go through different steps. In fact, PG can be chemically treated by mixing it with ammonium hydroxide aqueous solutions (5-20\%) for $24 \mathrm{~h}$ at $35^{\circ} \mathrm{C}$. It is then filtered and washed respectively with ammonium hydroxide solution $(0.5 \%)$ and water before it gets dried at $42^{\circ} \mathrm{C}$ temperature which reduces all impurities contents Singh., et al [17]. It can be also mixed with citric acid of 3-4\% of concentration Tayibi., et al. [13]. Several researchers indicated that PG purification can be achieved through many successive wash cycles using demineralized water Felfoul., et al. [14], eventually joined to its calcinations Al-Jabbari., et al. [16] or neutralization using calcium hydroxide Tayibi., et al. [13]. PG thermal treatment reaching $1000^{\circ} \mathrm{C}$ gave also good results Singh et Garg [17].

Hence, as PG purification procedures are relatively long based on thermal and/or chemical treatments, valorization potentials are quite limited especially in Tunisia which has the second/forth natural field worldwide. The management of the produced PG which can increase by 12 Million tons annually is a big challenge to the concerned authorities. Tunisia cannot be evolved in PG massive valorization, but massive storage, at least in the very short term CTG (2014).

\section{Problems with PG massive storage - Tunisia case study}

The deposit of Phosphogypsum into embankments allows storing big quantities of this residue in the vicinity of the production sites. However, these embankments can extend to important areas and height. As the embankments heights and areas increase, several environmental and structural problems appear as a consequence of PG massive storage.

\section{Environmental concerns - Taparura}

Phosphogypsum produced by the NPK factory, Tunisia, was deposited in the coast of Sfax resulting in the accumulation of a large square phosphogypsum stack close to the harbour and town (Figure 2.a). The stack, which covered an area of approximately 50 ha and reached a height of up to $8 \mathrm{~m}$ above sea level, was surrounded by a crusty layer of phosphogypsum with an area of 90 ha and a depth of up to 3 m IAEA [2]. This caused Sfax coast contamination and a remediation project was launched.
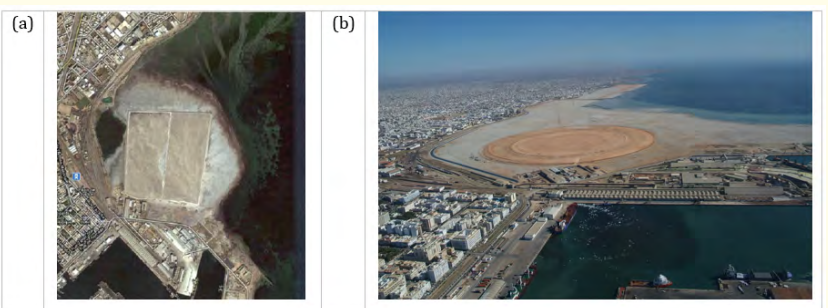

Figure 2: Aerial view of NPK factory deposit site (a) before remediation (b) after remediation.

For Million tons of contaminated materials were removed from the sea and, then, stored on land, to consolidate these residues into a designed central containment. The central containment is a circular terraced structure with a diameter of approximately $0.9 \mathrm{~km}$, an area of $55 \mathrm{ha}$, a maximum height of $16 \mathrm{~m}$ and a 1 in 5 slope (Figure $3)$. An existing layer of consolidated clay underlies the structure. A layer of uncontaminated soil was used to cap the material contained within the structure (Figure 2.b). The soil thickness varied from $0.8 \mathrm{~m}$ (on the top and terraces) to $2 \mathrm{~m}$ on the slopes (Figure 3) IAEA [2]. 


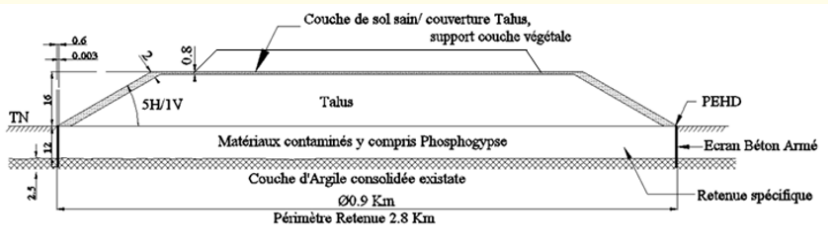

Figure 3: Simplified profile of the remediated PG stack IAEA (2013).

The groundwater level below the remediated stack is constantly monitored by automatic systems IAEA [2].

\section{Geotechnical concerns}

In 2012, it was revealed that the wet PG embankment of Sfax City (Table 1 ) with $56 \mathrm{~m}$ height, $53 \mathrm{Ha}$ area and $32^{\circ}$ slope can only be of $70 \mathrm{~m}$ height maximum Bouassida [4]. This embankment can reach $100 \mathrm{~m}$ in height if geotextile reinforcement will be operated. This deposition process is well recommended to ensure better interaction between the embankment and the existing ground surface. Using the dry deposited process, the area of the PG embankment of Skhira City (Table 1 ) covers $112 \mathrm{Ha}$ with two elevation levels of $25 \mathrm{~m}$ and $55 \mathrm{~m}$ in 2013 Chaari [5].

\begin{tabular}{|c|c|c|c|c|c|c|}
\hline $\begin{array}{l}\text { Deposited } \\
\text { embankment }\end{array}$ & \multicolumn{3}{|c|}{$\begin{array}{c}\text { Dry process Bouassida (2007) } \\
\text { and Chaari (2013) }\end{array}$} & \multicolumn{3}{|c|}{$\begin{array}{c}\text { Wet process } \\
\text { Bouassida (2012) }\end{array}$} \\
\hline Area (Ha) & \multicolumn{3}{|c|}{53} & \multicolumn{3}{|c|}{112} \\
\hline Height (m) & \multicolumn{3}{|c|}{56} & \multicolumn{3}{|c|}{ elevation: $25 \mathrm{~m}$ and $55 \mathrm{~m}$} \\
\hline $\begin{array}{l}\text { Geometry and shear } \\
\text { strength parameters }\end{array}$ & Height (m) & $\mathrm{c}(\mathrm{kPa})$ & $\varphi\left({ }^{\circ}\right)$ & Height (m) & $\mathrm{c}(\mathrm{kPa})$ & $\varphi\left({ }^{\circ}\right)$ \\
\hline Layer 1 (upper) & 8 & 90 & 30 & 8 & 10 & 32 \\
\hline Layer 2 & 8 & 97.2 & 30 & 48 & 41.2 & 32.3 \\
\hline \multirow{2}{*}{ Layer 3} & $\mathrm{H}^{(*)}-16$ & 104.4 & 30 & & & \\
\hline & \multicolumn{3}{|c|}{ (Chaari, 2013) } & & & \\
\hline \multirow{2}{*}{ The whole embankment } & $\mathrm{H}$ & 85 & $31^{\circ}$ & & & \\
\hline & \multicolumn{3}{|c|}{ (Bouassida, 2007) } & & & \\
\hline Total settlements (m) & \multicolumn{3}{|c|}{$4.72-4.91$} & \multicolumn{3}{|c|}{0.86} \\
\hline Lat. displacement (m) & \multicolumn{3}{|c|}{$\approx 0.4$} & \multicolumn{3}{|c|}{ insignificant } \\
\hline General aspect & \multicolumn{3}{|c|}{$\begin{array}{l}\text { More damaging settlements and } \\
\text { displacements apart from the } \\
\text { cracks and the slope instability }\end{array}$} & \multicolumn{3}{|c|}{$\begin{array}{l}\text { Regular top and slope } \\
\text { Better mechanical behavior } \\
\text { of the embankment and the } \\
\text { ground surface }\end{array}$} \\
\hline
\end{tabular}

Table 1: Properties of dry and wet PG embankments.

However, the dry deposited process results in a damaged embankment profile, excessive settlements and lateral displacements. Therefore, a PG embankment of $100 \mathrm{~m}$ height cannot be achieved. A reinforcement of the embankment by High Density Polyethylene geotextile (HDPE) layers at increments of $4 \mathrm{~m}$ from $55 \mathrm{~m}$ elevation allows reaching $130 \mathrm{~m}$ of height. However, three main factors limit this solution: First, the Tunisian Phosphogypsum $\mathrm{pH}$ is found to be of 2.9 Ajam., et al. (2009) and about 3, Felfoul., et al. [14] which affects the integrity of HDPE layers. Second, over time, there will be an accumulation of HDPE layers partially included into the embankment inferior layer which is assimilated to a stratum and does not require any reinforcement. Third, the study did not take into consideration the observed cracks within the embankment as reported by TCG engineers. 
Phosphogypsum Management Perspectives. Massive Valorization or Massive Storage?

Geotechnical characterization of a heterogeneous and chemically evolutive material is not evident. In fact, the chemical composition of Phosphogypsum depends on the origin of the phosphate ore, the manufacturing process, the efficiency of the plant and the age of the deposit Choura., et al. [19], Sahu., et al. [20]. These characteristics evolve over time like the soluble $\mathrm{P}_{2} \mathrm{O}_{5}$ which content increases as the PG gets older due to rain wash for example Felfoul., et al [14]. The color of Phospogyosum is dark at recent age Maazoun and Bouassida [6]. Its unit weight evolves as it gets drained and self-weight compacted and its specific unit weight is of $23.1 \mathrm{kN} / \mathrm{m}^{3}$. Its specific color and smell as well as its low specific unit weight reveal the presence of organic matter. The mechanical characteristics of the wet deposited Phosphogypsum over time were studied basing on three specimens: one extracted outlet filter and the others aged 10 and 50 years respectively and superficial Felfoul., et al. [14]. The study proved that the best bearing capacity is obtained for the specimen aged 10 (CBR=51\% compared to $49 \%$ and $5 \%$ for SP3 and SP1 respectively) as well as for the best shear strength ( $c=73 \mathrm{kPa}$ and $\varphi=37^{\circ}$ ) and a better mechanical performance and behavior to water. In addition, the fresh Phosphogypsum wash allowed improving the compressive strength which reveals that the decrease of acid and organic contents enhances the compressive strength of Phosphogypsum. Hence, the chemical evolution of Phosphogypsum is essentially due to the variation of geotechnical parameters rather than its age Felfoul., et al. [14].

In addition to Phosphogypsum mechanical aspect, observations deduced from field visits carried out in March 2017 proved the presence of water retained within the embankment mass Maazoun and Bouassida [6]. At a larger scale, experience with dry storing indicates that the lower layer of the embankment will be saturated even in desert, in arid climate and without rain infiltration due to gypsum self-weight consolidation and settlement Fuleihan [21]. This occurs to some extent in all dry stacks even when Phosphogypsum is well filtered (water $\backslash$ content $<<25 \%$ ).

New alternatives for phosphogypsum management recuperation of old/ abandoned embankments

PG storage into embankment can absorb important quantities of this residue instead of rejecting it into the seas. However, PG embankments start to show structural and geotechnical problems as their height reach critical elevations. As PG valorization is quiet limited especially for the PG purification high cost, new alternatives should be found to reduce land use for Pg storage. The recu- peration of the existing dry deposited PG embankment of Skhira City, Tunisia, and its reuse as support for a new wet deposited one is an alternative that may help optimizing storage areas. Phosphogypsum time dependent aspect was considered in the numerical simulation carried out. The wet deposit cinematic was also taken into consideration Maazoun and Bouassida [6].

All the materials and methods that are used to complete the study should be mentioned.

\section{Results and Discussion}

Results and discussion must illustrate and interpret the reliable results of the study.

\section{Conclusion}

Conclusion should reflect and elucidate how the results correspond to the study presented and provide a concise explanation of the allegation of the findings. This paper highlighted the problematic challenges faced for Phosphogypsum management which knew considerable evolution depending essentially on environmental concerns. PG valorization is a promising alternative to solve its storage problems, especially in massive axis such as roads and agriculture. However, Phosphogypsum valorization is still limited to $15 \%$ of the worldwide produced quantity because of the high cost of its purification which makes it less competitive to natural gypsum. Till putting PG valorization in action, its storage into embankments is a temporary alternative to manage it. Nevertheless, PG storage is equally limited by the storage areas shortage and the critical heights that may reach the embankments. This evolve that the existing storage areas, either abandoned or still in exploitation, should be recuperated, rehabilitation and reused for PG storage with more intensive quantities. Foundation amelioration can be recommended for this purpose.

\section{Acknowledgements}

The authors greatly acknowledge the support provided by the research development service of the Tunisian Chemical Group along with collaborative project with the National Engineering School of Tunis during the progress of PhD prepared by the first author.

\section{Conflict of Interest}

There is no financial interest or any conflict of interest, between the authors and any institution or individuals in regard to the content of this paper. 


\section{Bibliography}

1. World Population Prospects., July, United Nations, Department of Economic and Social Affairs, File POP/2: Average annual rate of population change by major area, region and country 1 (2015): 1950-2100.

2. International Atomic Energy Agency IAEA - Vienna. Radiation Protection and Management of Norm Residues In The Phosphate Industry (2013).

3. Bouassida M. Étude de stabilité du terril de phosphogypse de Skhira. Rapport d'étude géotechnique. Université de Tunis El Manar, ENIT 1 (2007): 1.

4. Bouassida M. Étude de stabilité du terril de phosphogypse de Sfax, Rapport d'étude géotechnique, Université de Tunis El Manar, ENIT 1 (2012): 1.

5. Chaari A. Stabilité d'un terril de phosphogypse, Projet de fin d'études, Ecole Nationale d'Ingénieurs de Tunis 1 (2013): 1.

6. Maazoun H and Bouassida, M. On Phosphogypsum Management Challenges: Proceedings of GeoMEast 2018 International Congress and Exhibition: "Sustainable Civil Infrastructures: Structural Integrity”, Egypt (2018).

7. Hilton J. Phosphogypsum (PG): Uses and Current Handling Practices Worldwide - Chairman, Aleff Group, Lakeland FL, London UK - The 25th Annual Lakeland Regional Phosphate Conference (2010).

8. International Maritime Organisation, Convention on the Prevention of Marine Pollution by Dumping of Wastes and Other Matter, 1972, as amended (2006).

9. Moalla R., et al. "Phosphogypsum purification for plaster production: A process optimization using full factorial design". Environmental Engineering Research 23 (2017): 36-45.

10. Valverde-Palacios I., et al. "Geotechnical Risk and Environmental Impact: the Stability of Phosphor-Gypsum Embankments in SW Spain". Electronic Journal of Geotechnical Engineering (2011): 16.

11. Living with Danger: In investigation of phosphogypsum pollution in the phosphate fertilizer industry, Sichuan Province, China.

12. WWW.Reuters.com New Wales - Gypstack extension project description, Mosaic co phosphate fertilizer facility - Florida.
13. Tayibi H., et al. "Environmental impact and management of phosphogypsum". Journal of Environmental Management 90.8 (2009): 2377-2386.

14. Felfoul HS., et al. "Gestion des sous-produits industriels et développement durable: cas du Phosphogypse de Sfax (Tunisie)". Sciences and Technologie. B, Sciences de l'ingénieur (2005): 66-81.

15. Colombel JH. Utilisation du Phosphogypse en assises traitées aux liants hydrauliques, chapitre II: le Phosphogypse: utilisation d'un sous produit industriel en technique routière. LPC, numéro spécial VII, Paris, 1978.

16. Al-Jabbari S., et al. "The physical methods for purification of the phosphogypsum for using it as building material". Journal of Building Research and Science Research Council Baghdad 7 (1988): 49-69.

17. Singh M., et al. "Purifying phosphogypsum for cement manufacture". Construction and Building Materials 7.1 (1993): 3-7.

18. Hachicha M. Les sols salés et leur mise en valeur en Tunisie. Science et changements planétaires/Sécheresse 18 (2007): 45-50.

19. Choura M., et al. "Study of the mechanical strength and leaching behavior of phosphogypsum in a sulfur concrete matrix". IOSR Journal of Environmental Science, Toxicology and Food Technology (2019): 8-13.

20. Sahu SK., et al. "Natural radioactivity assessment of a phosphate fertilizer plant area". Journal of Radiation Research and Applied Sciences 7 (2014): 123-128.

21. Fuleihan NF. Phosphogypsum Disposal - The Pros AND Cons of Wet Versus Dry Stacking. Procedia Engineering 46 (2012): 195-205.

\section{Volume 3 Issue 8 August 2019 (C) All rights are reserved by Hajer Maazoun and Mounir Bouassida.}

